\title{
Performance enhancement in a multilevel inverter fed PTC induction motor drive by optimal voltage vector selection
}

\author{
Himabindu T. ${ }^{1}$, A.V.Ravi Teja ${ }^{2}$, G. Bhuvaneswari ${ }^{3}$, Bhim Singh ${ }^{4}$ \\ ${ }^{1}$ Departement of Electrical and Electronics Engineering, BITS-Pilani, Hyderabad campus, India \\ ${ }^{2}$ Departement of Electrical Engineering, IIT Ropar, India \\ ${ }^{3,4}$ Departement of Electrical Engineering, IIT Delhi, India
}

\begin{tabular}{l}
\hline \hline Article Info \\
\hline Article history: \\
Received Sep 25, 2018 \\
Revised Nov 19, 2018 \\
Accepted Feb 5, 2019 \\
\hline
\end{tabular}

Keywords:

Induction motor drive (IMD)

Multilevel inverter

Neutral clamped Inverter

Predictive torque control (PTC)

Torque ripple

\begin{abstract}
This paper proposes a novel predictive control strategy for a multilevel inverter fed Induction Motor Drive (IMD) with optimal voltage vector selection at every sampling interval. The proposed predictive control strategy, apart from enhancing the dynamic speed and torque responses of the drive, strives to reduce the number of switching transitions by choosing optimal voltage vector, thereby reducing the switching losses significantly. The algorithm put forth here chooses the most suitable switching state among the redundant switching combinations, such that minimum number of switches change their states from the previous switching combination to the present one. This results in perceptible reduction in the switching losses thereby increasing the efficiency of the converter. The proposed Predictive Torque Control (PTC) strategy is modeled and simulated in Matlab/ Simulink environment and the results are reported for a 2-level and 3-level inverter fed IMD configurations. The results demonstrate the effectiveness of the proposed PTC for both 2-level and 3-level inverter fed IMDs.
\end{abstract}

Copyright (C) 2019 Institute of Advanced Engineering and Science. All rights reserved.

\section{Corresponding Author:}

Himabindu T,

Department of Electrical and Electronics Engineering,

BITS-Pilani Hyderabad Campus,

Hyderabad, India.

hima.bindu210@gmail.com

\section{INTRODUCTION}

Adjustable speed drives (ASD) find immense applications in various industries such as textile mills, paper mills, printing presses, cement mills, oil drilling, process control and transport sectors. They are also widely used in commercial sectors especially for heating, ventilating and air-conditioning (HVAC) systems $[1,2]$. Field Oriented Control (FOC) and Direct Torque Control (DTC) are two accurate control techniques [3-5] which are commonly employed for controlling the ASDs so that fast dynamic response is obtained simultaneously tracking the reference speed and torque exactly. FOC involves coordinate transformations; it requires the exact position of the air gap flux vector. But, DTC is not as computation intensive as FOC; so, DTC is preferred in many of the ASD applications where low speed operation is not very common.

An improved DTC technique with Space vector modulation is proposed in [6] which eliminates undesired torque and current ripples effectively. A performance comparison of DTC based IMD with P and PI controllers is presented in [7]. A neuro-fuzzy based adaptive controller for accurate speed estimation in a sensorless direct torque controlled induction motor drive (IMD), working at low speeds, is discussed in [8] wherein model reference adaptive controller is being employed as a rotor flux observer. There are a large number of papers on the modeling and simulation of IMDs in MATLAB, whereas [9] describes complex real-time simulation of IMD using RT-Lab software while it is running simultaneously on several personal 
computers. Challenges faced while executing these simulations are outlined in this paper; some suggestions are proposed to overcome these issues; finally, solutions obtained henceforth are presented in this paper.

Predictive control scheme associated with DTC described in $[10,11]$ diminishes both torque and flux ripples; it makes multiple predictions within one sampling interval. The proposed predictive algorithm in [12] has distinctly two parts: the first part arrives at the predictive stator reference flux vector; the second part aids the drive in tracking the stator reference flux by selecting either a zero voltage vector or an active vector. A comparison between the classical DTC technique and predictive torque control (PTC) has been carried out in [13]; similarly, the DTC technique has been compared with forced machine current control (FMCC) in [14]. It is very clear that PTC offers a number of advantages over classical DTC such as lesser torque and current ripples and accurate and faster tracking of speed and torque. A two level VSC based predictive DTC for a doubly fed IMD presented in [15] reduces the rotor flux and electromagnetic torque ripples, with a smaller value of switching frequency. Thus, this can easily be employed even in very high power applications. Based on the present stator voltage, a vector prediction DTC has been derived in [16], so as to achieve the desirable flux and torque responses.

The predictive control approach has been extended even to multilevel inverters [17] to achieve excellent drive characteristics. However, in most of the DTC drives, high switching frequency due to the use of hysteresis controllers and associated switching losses are major issues, especially when a multi-level inverter is used to feed the IMD. Furthermore, the ripples observed in torque and flux, particularly in low speed operation, pose a major problems to sensitive loads. In this paper, a novel predictive control scheme for a three-level diode clamped VSI fed IMD is presented for reducing the torque ripples; further, its performance is compared with a two-level inverter fed drive. For implementing predictive control, the present values of drive parameters such as its current and flux are utilized to predict the behavior of the complete drive system during the next time step. This enables the controller to apply a suitable combination of voltage vector(s) such that the torque ripples could be minimized. The proposed predictive control algorithm is analyzed and the responses are studied for different load and speed conditions of the IMD using Matlab/Simulink. Whenever there is a redundancy in the switching states of the devices to obtain a particular voltage space vector, suitable choice is made so that the number of switching transitions is kept to a minimum. The switching losses, the total harmonic distortion (THD) in the stator current, current and torque ripples, overshoot and settling time are analyzed in detail in this work. This paper is organized as follows: Section I presents an introduction to the problems associated with classical DTC and then puts predictive control using mulita-level inverters in perspective. Section II discusses the optimal voltage vector selection (wherever redundancy exists) for the PTC IMD. Section III discusses modeling and simulation of the complete drive scheme where simulation models are explained. Section IV presents the simulation results followed by conclusion in Section V.

\section{EFFICIENT VOLTAGE VECTOR PLACEMENT FOR PREDICTIVE TORQUE CONTROL}

Power Electronics is an enabling technology that has improved the efficiency and performance of $\mathrm{AC}$ drives in a significant manner making them applicable to a plethora of industrial functions. In view of increasing drive applications, new control strategies are developed to achieve faster dynamic response, simplicity of implementation and lower parameter sensitivity. The concept of predictive control strategy designed for IMD [18], predicts the future behavior of the drive in terms of torque and stator flux, by using the information at the present instant of time. The block diagram of the PTC for three level VSI fed IMD is shown in Figure 1.

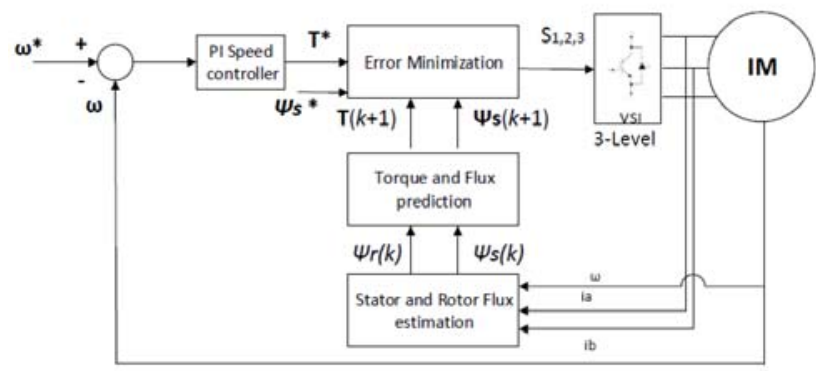

Figure 1. Block Diagram of PTC Scheme

Int J Pow Elec \& Dri Syst, Vol. 10, No. 2, June 2019 : 801 - 812 
The execution of predictive control algorithm is done in three steps: (i) estimation of variables in the present step (ii) prediction of the future values of the controlled variables and (iii) optimization of the output according to the previously specified control law. Predictions are made for every available switching combination of the inverter. Hence, reference is accurately tracked by selecting the suitable voltage vector for which minimum error is maintained throughout the process. From the block diagram, it can be seen that the space phasor variables which cannot be measured such as Rotor flux $\left(\psi_{\mathrm{r}}\right)$, Stator flux $\left(\psi_{\mathrm{s}}\right)$ and electromagnetic torque are calculated in the estimation block by sensing a-phase and b-phase stator currents $\left(\mathrm{i}_{\mathrm{a}}, \mathrm{i}_{\mathrm{b}}\right)$. The equations involved are presented below :

$$
i_{s}=\frac{2}{3}\left(i_{a}+a i_{b}+a^{2} i_{c}\right)
$$

Where $i_{c}=-\left(i_{a}+i_{b}\right)$

$$
a=e^{j 2 \pi / 3}=\frac{-1}{2}+j \frac{\sqrt{3}}{2}
$$

$a^{2}=e^{j 4 \pi / 3}=\frac{-1}{2}-j \frac{\sqrt{3}}{2}$

Stator flux is estimated using the stator voltage :

$$
V_{s}=R_{s} i_{s}+\frac{d \psi_{s}}{d t}
$$

Estimation of stator flux at $k^{\text {th }}$ instant for a sampling time $T_{s}$ is given in (6). This is obtained after discretization of 5 using Euler's formula.

$$
\widehat{\psi_{s}}(k)=\widehat{\psi_{s}}(k-1)+T_{s} V_{s}(k)-R_{s} T_{s} i_{s}(k)
$$

Similarly, from the flux linkage, the rotor flux estimation can be done as follows:

$$
\widehat{\psi_{r}}(k)=\frac{L_{r}}{L_{m}} \widehat{\psi_{s}}(k)+i_{s}(k)\left(L_{m}-\frac{L_{r} L_{s}}{L_{m}}\right)
$$

Estimation of stator and rotor flux at $k^{\text {th }}$ instant can be completed by using (6) and (7). Now stator flux and torque predictions at $(k+1)^{\text {th }}$ step are obtained as:

$$
\begin{aligned}
& \psi_{s}^{p}(k+1)=\widehat{\psi}_{s}(k)+T_{s} V_{s}(k)-R_{s} T_{s} i_{s}(k) \\
& T^{p}(k+1)=\frac{3 p}{2} \operatorname{Im}\left\{\bar{\psi}_{s}^{p}(k+1) i_{s}^{p}(k+1)\right\}
\end{aligned}
$$

Term (9) shows that the torque prediction at $(k+1)^{\text {th }}$ step is dependent on predicted values of stator flux and stator current at $(k+1)^{\text {th }}$ step. Predicted stator current is given as:

$$
\begin{aligned}
& i_{s}^{p}(k+1)=\left(1+\frac{T_{s}}{T_{\sigma}}\right) i_{s}(k)+\frac{T_{s}}{\tau_{\sigma}+T_{s}}\left[\frac{1}{R_{\sigma}}\left\{\left(\frac{k_{r}}{\tau_{r}}-k_{r} j \omega\right) \widehat{\psi}_{r}(k)+V_{s}(k)\right\}\right] \\
& \text { where } k_{r}=\frac{L_{m}}{L_{r}}, R_{\sigma}=R_{s}+R_{r} k_{r}^{2}, T_{\sigma}=\left(1-\frac{L_{m}^{2}}{L_{s} L_{r}}\right) \frac{L_{s}}{R_{\sigma}} \text { and } \tau_{r}=\frac{L_{r}}{R_{r}} .
\end{aligned}
$$

For a three level inverter (shown in Figure 2), 24 active vectors and 3 zero vectors are possible depending upon the switching combinations; i.e., total 27 switching states are obtained, out of which, (6) are redundant switching states. Therefore, the predicted variables such as current, flux and torque at $(k+1)^{\text {th }}$ instant, i.e. (where $h \in[0,1, \ldots, 18]$ ) are calculated in the proposed PTC algorithm for zero voltage vectors and non-redundant non-zero voltage vectors. 


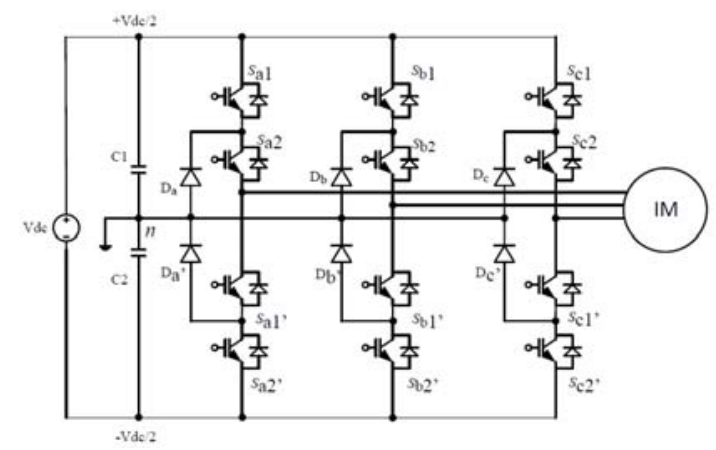

Figure 2. Three level Neutral clamped VSI fed IMD

In the error minimization block, predictions of the controlled variables at $(k+1)^{\text {th }}$ instant (stator flux, torque and stator current) are obtained for every possible value of $V_{s}$. The error $\left(\varepsilon_{h}\right)(11)$ is the difference between the predicted and reference values of controlled variables. Finally, the switching state is selected for which the error is minimum and then this voltage vector applied to the motor by switching appropriate devices in the inverter.

$$
\varepsilon_{h}=\left|T^{*}-T^{p}(k+1)_{h}\right|+\lambda_{\psi}\left|\psi_{s}^{*}-\psi_{s}^{p}(k+1)_{h}\right|
$$

where $h \epsilon[0,1, \ldots, 18])$ and $\lambda_{\psi}$ is weighting factor chosen as the ratio of nominal torque to nominal stator flux.

In the proposed PTC algorithm, there are three ways of applying zero vector (switch combinations, 000,111 and 222). Similarly redundant states are observed for some other non-zero voltage vectors as well (example $\mathrm{V}_{14}$ and $\mathrm{V}_{22}, \mathrm{~V}_{13}$ and $\mathrm{V}_{21}$ etc.) as observed in space vector diagram (Figure 3).

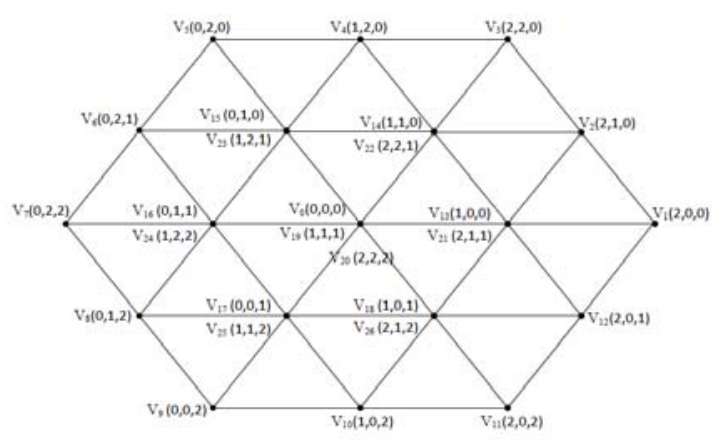

Figure 3. Space vector diagram of a three level inverter

\section{MODELLING AND SIMULATION}

The number of switchings during any transition will be reduced if the voltage vector (especially where there is redundancy) nearest to the previous vector is chosen as per the switching states.

Figure 4 presents the logic where it can be observed that if zero vector needs to be applied in the $(k+1)^{\text {th }}$ instant, then in a three-level inverter case there are three zero vector options namely $\mathrm{V}_{0}, \mathrm{~V}_{19}$ and $\mathrm{V}_{20}$. Among these three zero voltage vectors, $V_{0}$ is selected if the previous vector is one of $\left(V_{0}, V_{1}, V_{5}, V_{9}, V_{13}\right.$, $\left.\mathrm{V}_{15}, \mathrm{~V}_{17}\right)$ as this will require the transition of only one of the three-phases. Similarly in the case of non-zero voltage vector with redundant states, (i.e. $V_{13}-V_{21}, V_{14}-V_{22}, V_{15}-V_{23}, V_{16}-V_{24}, V_{17}-V_{25}, V_{18}-V_{26}$ ), the voltage vector with least number of switching transition is selected. For example voltage vector $V_{21}$ is selected while considering the redundant vector pair of $V_{13} \& V_{21}$, if the previous vector is one of $\left(V_{2}, V_{12}\right.$, $\mathrm{V}_{16}, \mathrm{~V}_{19}, \mathrm{~V}_{21}, \mathrm{~V}_{22}, \mathrm{~V}_{26}$ ), as this will require the transition of only one phase switches. Table 1 illustrates the reduction in the total number of switching transitions caused by this kind of selection of voltage vectors.

Int J Pow Elec \& Dri Syst, Vol. 10, No. 2, June 2019: $801-812$ 
Table 1. No. of Switchings for a duration of 14 secs, with a switching frequency of $20 \mathrm{kHz}$ with and without efficient choice of voltage vector in $(k+1)^{\text {th }}$ instant.

Table 1. Eduction in the total number of switching transitions

\begin{tabular}{|c|c|c|}
\hline Level of the Inverter & $\begin{array}{l}\text { No. of Switching Transitions without } \\
\text { Efficient choice of voltage vector }\end{array}$ & $\begin{array}{l}\text { No. of Switching Transitions with } \\
\text { Efficient choice of voltage vector }\end{array}$ \\
\hline Two Level Inverter & 0.3684 million & $\begin{array}{l}0.3664 \text { million } \\
(0.54 \% \text { less switching })\end{array}$ \\
\hline Three Level Inverter & 0.3749 million & $\begin{array}{l}0.3559 \text { million } \\
(5.07 \% \text { less switching) }\end{array}$ \\
\hline
\end{tabular}

The flowcharts for selecting the efficient voltage vector with minimum switching transitions when zero vector is to be chosen and non-zero vector with redundancy is to be chosen are shown in (Figure 4) and (Figure 5) respectively.

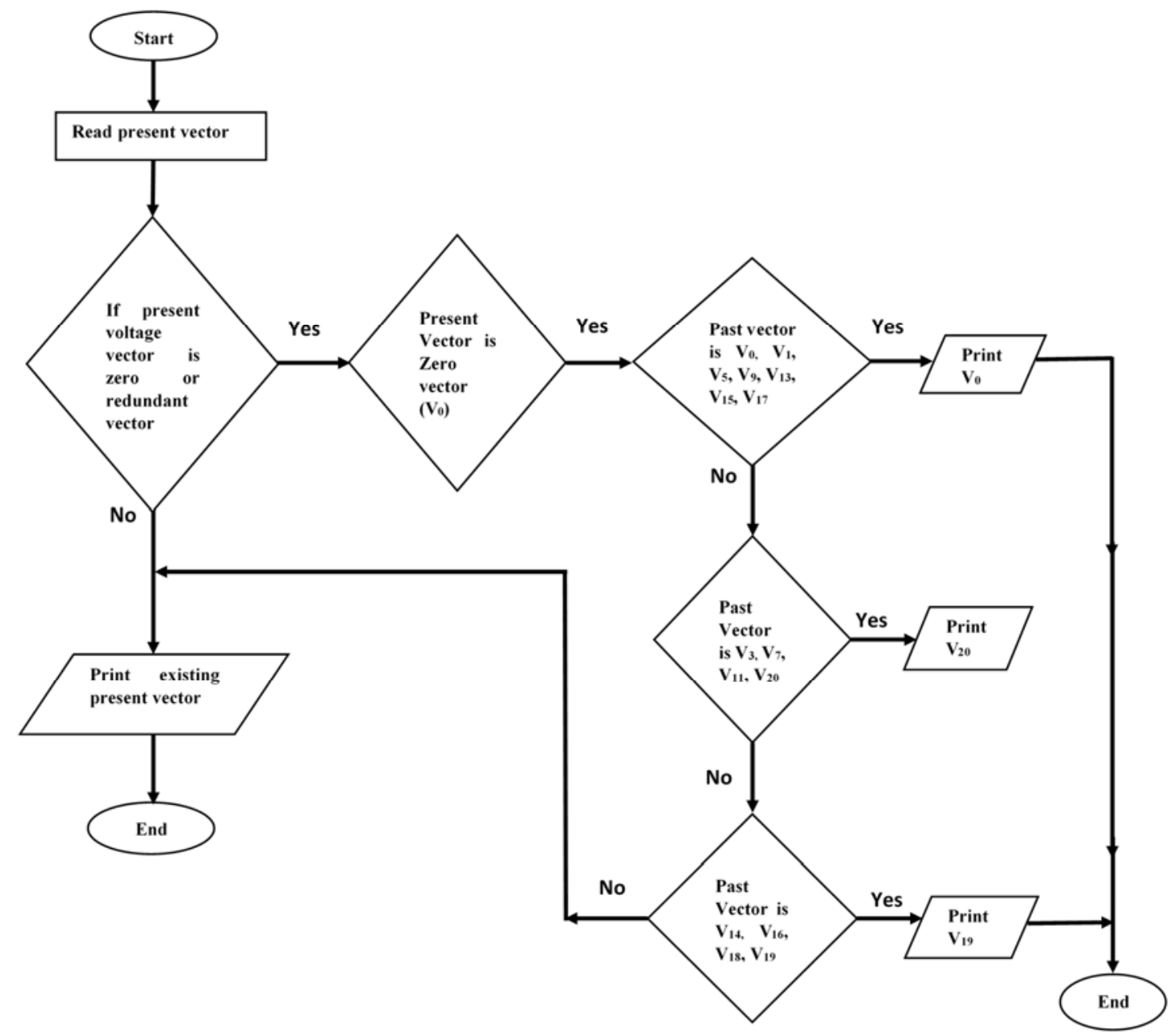

Figure 4. Flowchart for selecting the efficient voltage vector with minimum switching when zero vector occurs. 


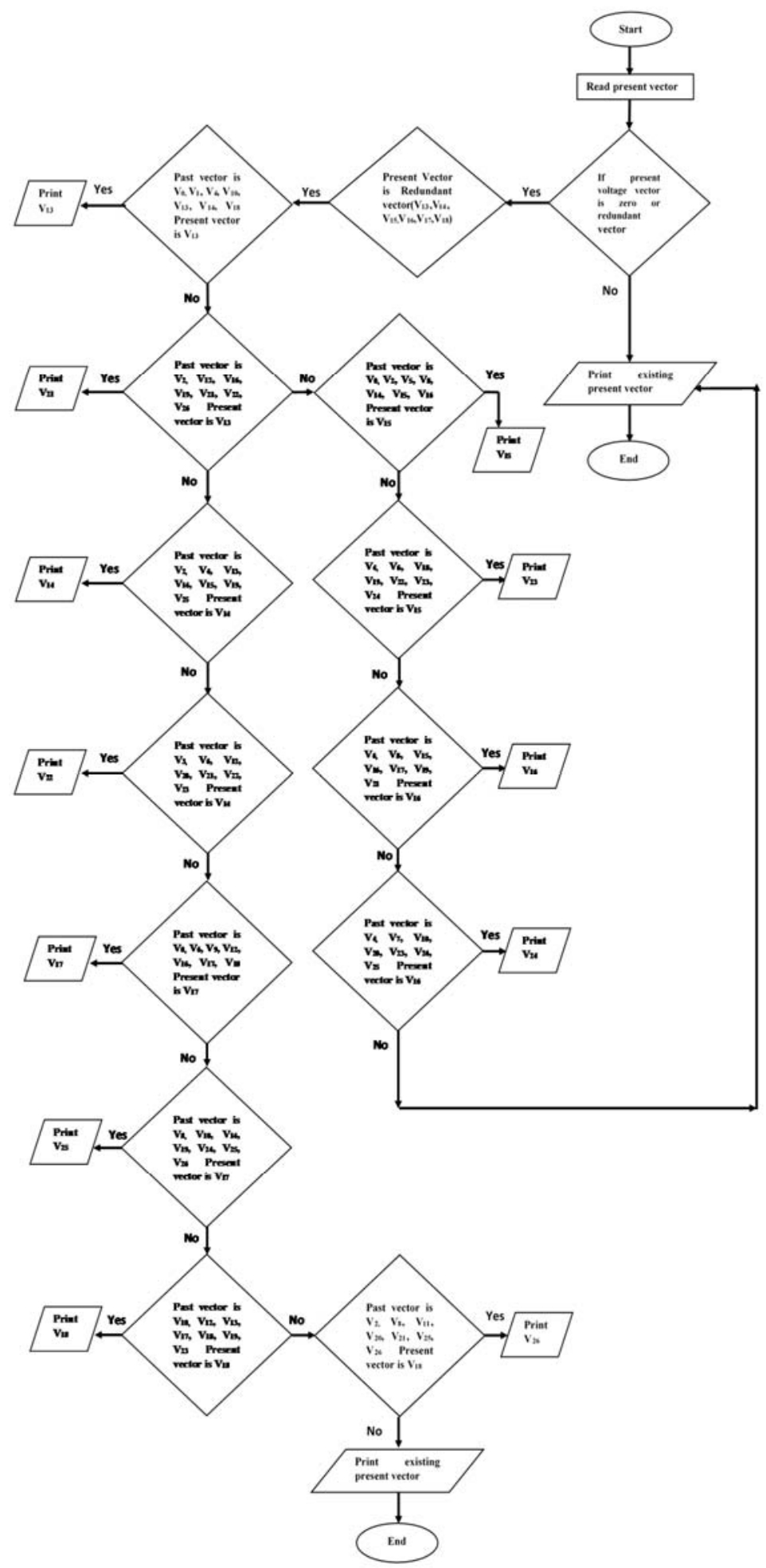

Figure 5. Flowchart for selecting the efficient voltage vector with minimum switching when redundant vector occurs 


\section{SIMULATION RESULTS}

\subsection{Proposed PTC algorithm for three level inverter fed IMD}

The proposed algorithm applied to multilevel VSI fed IMD is simulated in Matlab/Simulink environment. Induction motor parameters are given in Table 2.

Table 2. Induction Machine Rating and Parameters.

\begin{tabular}{lll}
\hline Parameter & Symbol & Nominal Value \\
\hline Rated Shaft Power & - & $4 \mathrm{~kW}$ \\
Line to Line Voltage & - & $400 \mathrm{~V}$ \\
Rated Speed & - & $1430 \mathrm{rpm}$ \\
Pole pair & $\mathrm{P}$ & 2 \\
Stator Self-Inductance & $\mathrm{Ls}$ & $0.1780 \mathrm{H} / \mathrm{ph}$ \\
Rotor Self-Inductance & $\mathrm{Lr}$ & $0.1780 \mathrm{H} / \mathrm{ph}$ \\
Magnetizing Inductance & $\mathrm{Lm}$ & $0.1722 \mathrm{H} / \mathrm{ph}$ \\
Stator Resistance & $\mathrm{Rs}$ & $1.405 \Omega / \mathrm{ph}$ \\
Rotor Resistance & $\mathrm{Rr}$ & $1.395 \Omega / \mathrm{ph}$ \\
Machine Inertia & $\mathrm{J}$ & $0.0131 \mathrm{~kg}-\mathrm{m} \neg 2$ \\
\hline
\end{tabular}

Simulation results for the proposed algorithm are analyzed in terms Stator current ripples and Torque ripples in steady-state for the three-level case. Further, overshoot, settling time, and undershoot are observed during transient operating conditions such as a sudden change in load torque or reference speed. THD of the stator current is also observed. At steady-state, various operating conditions of the drive in terms of speed and load torque are shown in Figure 6 for a three-level inverter case with PTC algorithm with optimal vector placement. The applied speed reference (Nref) and the actual (Nact) speed coincide with each other as depicted in Figure 6a. The electromagnetic torque generated from the IM and the load torque reference obtained from speed loop error are shown in Figure 6b. In Figure $6 \mathrm{c}$ reference and actual values of stator flux are shown where constant stator flux of $0.8 \mathrm{~Wb}$ is observed and is maintained throughout. The torque ripple calculated at $25 \mathrm{~N}-\mathrm{m}$ load in Figure $6 \mathrm{~d}$ is found to be $0.4 \%$ of the reference value.

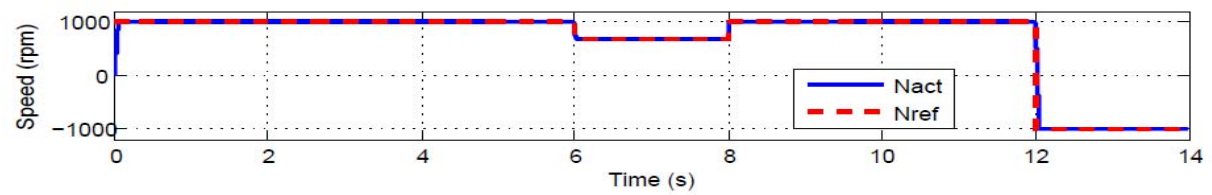

(a)

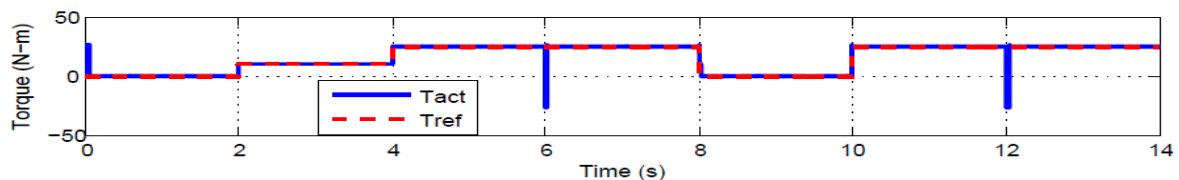

(b)

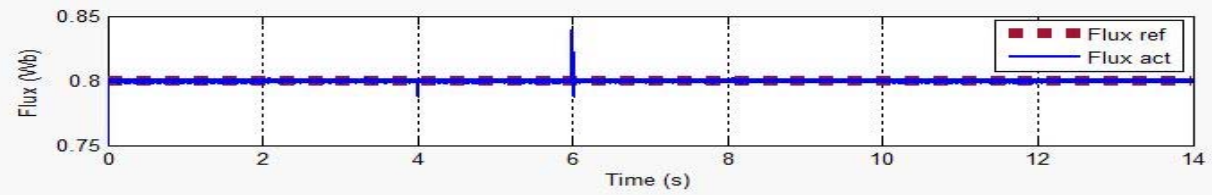

(c)

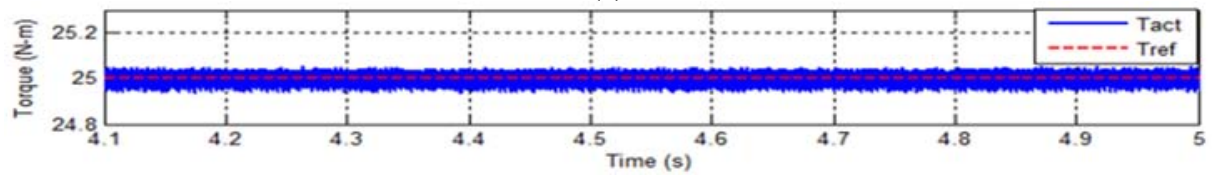

(d)

Figure 6. Response of the proposed PTC based three level Inverter fed IM Drive. (a) Reference (Nref) and Actual (Nact) speeds vs. time, (b) Reference (Tref) and Actual (Tact) Torque vs. time, (c) Reference and Actual Flux $(0.8 \mathrm{~Wb})$ vs. time (d) Torque ripple at $25 \mathrm{~N}-\mathrm{m}$.

Performance enhancement in a multilevel inverter fed PTC induction motor drive ... (Himabindu T) 


\subsubsection{Load change with speed reference being a constant}

Figure 7 illustrates a load change from 10 to $25 \mathrm{Nm}$ when rotor speed is maintained constant at 1000 rpm. The actual torque generated by the machine tracks the load torque as shown in Figure $7 \mathrm{a}$ where the overshoot and settling time are $0.29 \mathrm{~N}-\mathrm{m}$ and $0.9 \mathrm{~ms}$ respectively. At the instant of load change the rotor speed dip of around $3 \mathrm{rpm}$ was observed in Figure $7 \mathrm{~b}$. Further speed controller restores the rotor speed to the reference value. During load change, the variation of a-phase stator current is shown in Figure 7c.

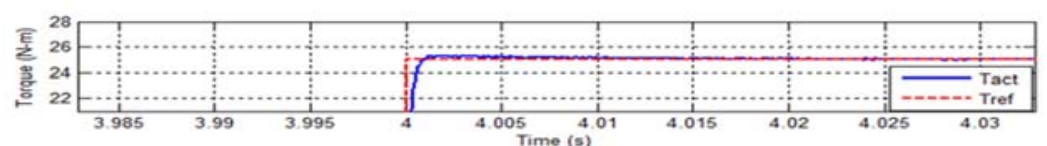

(a)

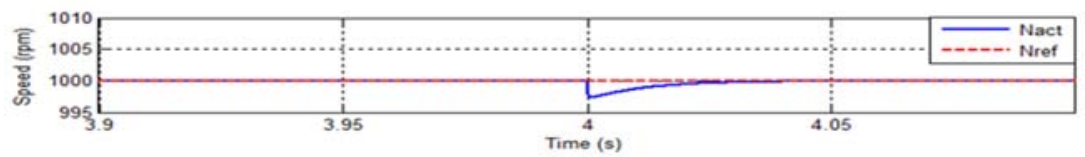

(b)

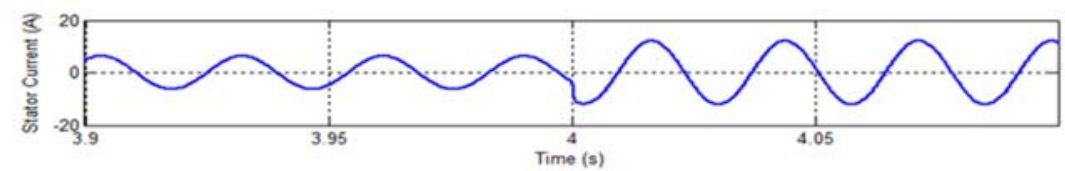

(c)

Figure 7. Response when Load Torque changes from 10 N-m to 25 N-m (a) Torque (b) Speed (c) Stator current in PTC based IM Drive fed by a Three-Level VSI.

\subsubsection{Speed change with Load constant}

A sudden speed change from 1000 to $680 \mathrm{rpm}$ in Figure 8 is demonstrated by keeping load torque constant at $25 \mathrm{~N}-\mathrm{m}$. The reference speed command tracks the machine speed with an overshoot of approximately $7 \mathrm{rpm}$ and settling time of $8 \mathrm{~ms}$ as shown in Figure 8a. The torque dips to $-27 \mathrm{~N}-\mathrm{m}$ as could be observed in Figure 8b, in order to facilitate fast response during speed change. The a-phase stator current is shown in Figure 8c. The THD of stator current in predictive torque control strategy for three level inverter fed IMD is observed to be $0.34 \%$ (Figure $8 d$ ).

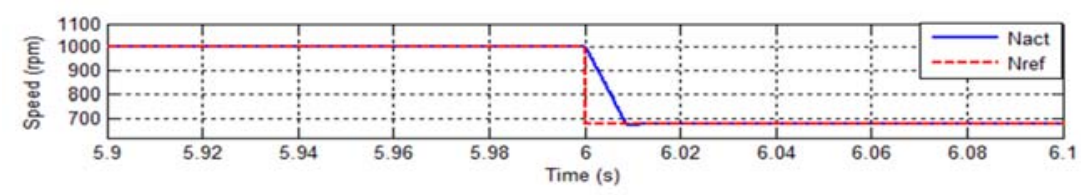

(a)

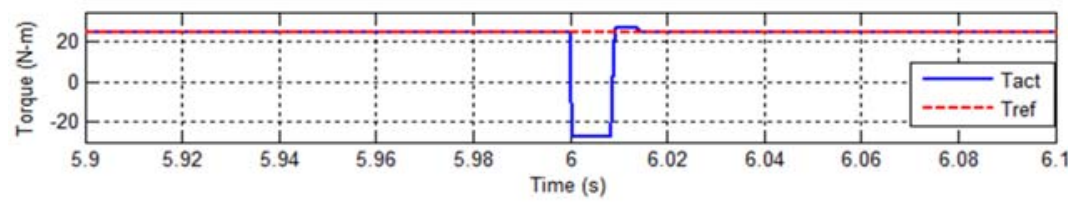

(b)

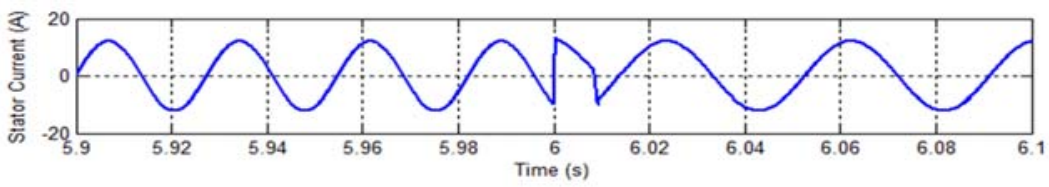

(c) 


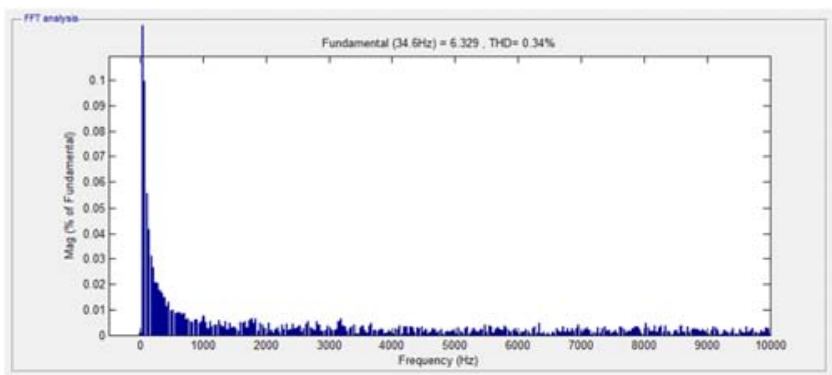

(d)

Figure 8. Response when speed changes from $1000 \mathrm{rpm}$ to $680 \mathrm{rpm}$ (a) Speed (b) Torque (c) Stator current (d) THD analysis in PTC based IM Drive.

\subsection{Comparison with 2-level inverter fed IMD}

The proposed algorithm is also applied similarly for a two-level inverter where zero vector is the only redundant state available. The efficient zero vector selection logic applied is shown in Table 3 [19]. Similar conditions used for a three-level inverter are tested here also and the corresponding results are shown in Figure 9. Both reference and actual values of speed (Figure 9a), torque (Figure 9c), and flux (Figure 9d) of $0.8 \mathrm{~Wb}$ are plotted. The load torque of $25 \mathrm{~N}-\mathrm{m}$ is enlarged in Figure 9e and steady-state torque ripple is found to be $0.6 \%$. The machine took around $0.11 \mathrm{~s}$ for reversal as depicted in Figure $9 \mathrm{~b}$.

Table 3. $(k+1)^{\text {th }}$ Zero Vector selection logic for 2-level inverter [19].

\begin{tabular}{cc}
\hline$(k+1)^{t h}$ vector to be applied & Previous Voltage Vector \\
\hline $\mathrm{V}_{0}$ & $\mathrm{~V}_{0}, \mathrm{~V}_{1}, \mathrm{~V}_{3}, \mathrm{~V}_{5}$ \\
$\mathrm{~V}_{7}$ & $\mathrm{~V}_{2}, \mathrm{~V}_{4}, \mathrm{~V}_{6}, \mathrm{~V}_{7}$ \\
\hline
\end{tabular}

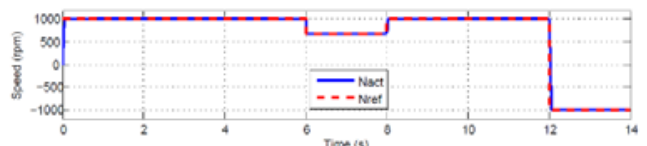

(a)

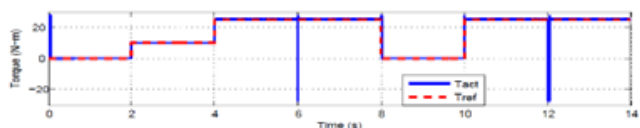

(c)

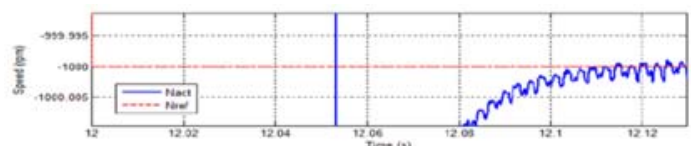

(b)

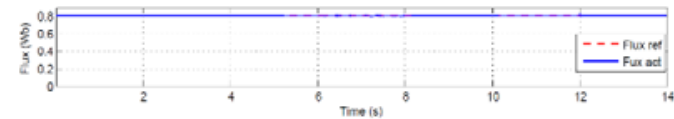

(d)

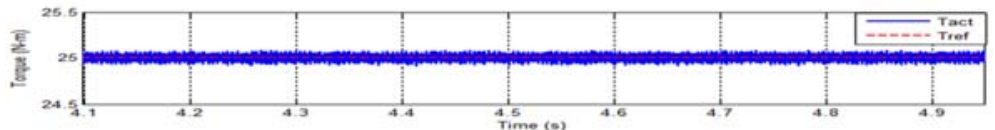

(e)

Figure 9. Response of the drive with proposed PTC algorithm for two level Inverter fed IMD (a) Reference (Nref) and Actual (Nact) speeds vs. time, (b) Expanded portion of speed tracking during machine reversal (c) Reference (Tref) and Actual (Tact) Torque vs. time, (d) Reference and Actual Flux (0.8 Wb) vs. time (e) Torque ripple at $\mathrm{Te}=25 \mathrm{~N}-\mathrm{m}$.

\subsubsection{Load change with speed constant}

The transient behavior of the IMD working with this algorithm is observed by applying a sudden change in load torque from $10 \mathrm{~N}-\mathrm{m}$ to $25 \mathrm{~N}-\mathrm{m}$ at $4 \mathrm{~s}$ as shown in Figure $10 \mathrm{a}$. It is observed that the torque overshoot is about $0.31 \mathrm{~N}-\mathrm{m}$ and settling time is $0.02 \mathrm{~s}$. During this load change, the rotor speed (Figure 10b) dips from 1000 to $997.27 \mathrm{rpm}$. The a-phase stator current is shown in Figure 10c. The THD of the stator current is found to be $0.91 \%$ in Figure $10 \mathrm{~d}$ where switching frequency is $20 \mathrm{KHz}$ and sampling time $2 \mu \mathrm{s}$. 


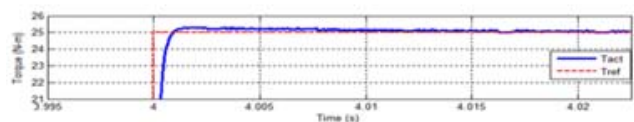

(a)

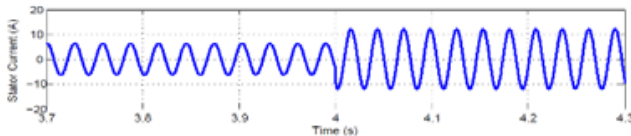

(c)

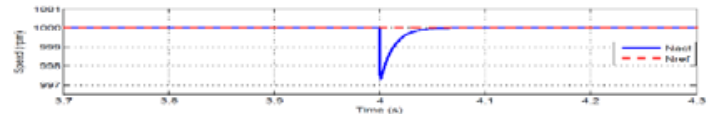

(b)

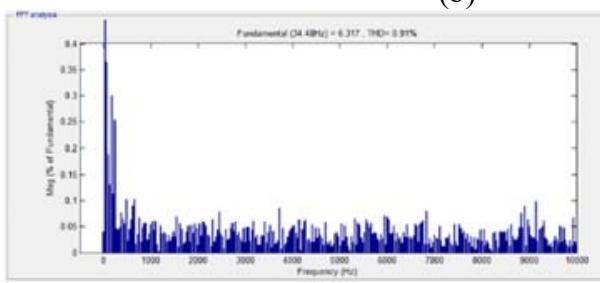

(d)

Figure 10. Response when Load Torque changes from $10 \mathrm{~N}-\mathrm{m}$ to $25 \mathrm{~N}-\mathrm{m}$ (a) Torque (b) Speed (c) Stator current (d) THD analysis with the proposed PTC algorithm in Two-Level VSI.

\subsubsection{Speed change with load constant}

Similarly, for a sudden change in the reference speed from 1000 to $680 \mathrm{rpm}$ at $6 \mathrm{~s}$ as shown in Figure $11 \mathrm{a}$, the speed overshoot is $8 \mathrm{rpm}$ and settling time is $0.014 \mathrm{~s}$. During this speed change, the torque and stator current are observed in Figs. $11 \mathrm{~b}$ and $11 \mathrm{c}$ respectively.

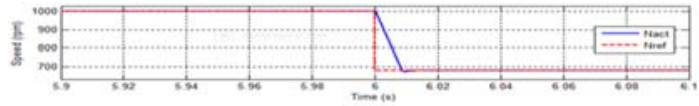

(a)

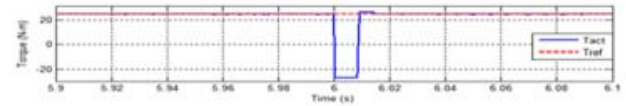

(c)

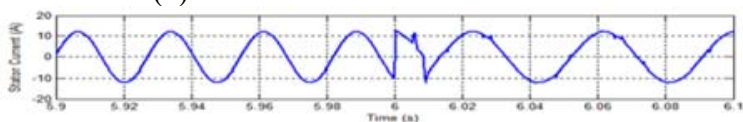

(d)

Figure 11. Response when speed changes from $1000 \mathrm{rpm}$ to $680 \mathrm{rpm}$ (a) Speed (b) Torque (c) Stator current with the proposed PTC algorithm.

It is very clear that the three level VSI has less torque and current pulsations as compared to a two level VSI fed DTC IMD. The proposed PTC algorithm with optimal voltage vector selection, thus, not only reduces the switching losses but also improves the performance in terms of torque and current pulsations and THD of stator current.

\section{CONCLUSION}

This paper presents a new PTC algorithm for 3-level VSI fed DTC IMD, with optimal voltage vector placement. The PTC algorithm has been applied to both two level and three level inverter fed IM drive. It is observed that the predictive torque control algorithm for three level inverter yields a better performance in terms of output current THD, torque ripple and current ripple, as compared to a two level inverter fed IMD. The proposed PTC algorithm is simple to implement and also improves the efficiency due to the reduction in the number of switchings. While $0.54 \%$ is the reduction in the number of switching transitions during the switching process in the proposed PTC algorithm for two level inverter fed IMD, the reduction in the three-level case is $5.07 \%$. The transient and steady state operating conditions (with the proposed control strategy) are analyzed in Matlab/Simulink environment and the results obtained show that the drive will be having reduced switching losses and improved efficiency than the classical DTC and PTC control strategies. 


\section{REFERENCES}

[1] A. Nabae, I. Takahashi, and H. Akagi,"A New Neutral-Point-Clamped PWM Inverter," IEEE Transactions on Industry Applications, vol. IA-17, no. 5, pp. 518-523, Sep. 1981.

[2] Kouro, S, M Malinowski, K Gopakumar, J Pou, L G Franquelo, Bin Wu, J Rodriguez, M A Pérez, and J I Leon,"Recent Advances and Industrial Applications of Multilevel Converters." IEEE Transactions on Electronics,vol. 57, no. 8 pp. 2553-2580, Aug. 2010.

[3] Nabil Farah, M. H. N. Talib, Z. Ibrahim, J. M. Lazi, Maaspaliza Azri,"'Self-tuning Fuzzy Logic Controller Based on Takagi-Sugeno Applied to Induction Motor Drives," International Journal of Power Electronics and Drive System (IJPEDS), vol. 9, No. 4, pp. 1967-1975, Dec. 2018.

[4] Takahashi, Isao, and Toshihiko Noguchi,"A New Quick-Response and High-Efficiency Control Strategy of an Induction Moto," IEEE Transactions on Industry Applications, vol. IA-22, no. 5, pp. 820-27, Sep. 1986.

[5] Depenbrock, M,'Direct Self-Control (DSC) of Inverter-Fed Induction Machine," IEEE Transactions on Power Electronics, vol. 3, no. 4, pp. 420-429, Oct. 1988.

[6] D. Casadei, G. Serra, and A. Tani, "Improvement of direct torque control performance by using a discrete SVM technique," in PESC 98 Record, 29th Annual IEEE Power Electronics Specialists Conference (Cat. No.98CH36196),Fukuoka, Japan, 1998, vol. 2, pp. 997-1003.

[7] Ranjit Kumar Bindal, Inderpreet Kaur,"Comparative analysis of P and PI controller using with DTC for Three Phase Induction Motor," International Journal of Robotics and Automation, vol.7, no.4, Dec 2018.

[8] Mini R, Shabana Backer P., B. Hariram Satheesh, Dinesh M. N,"Low Speed Estimation of Sensorless DTC Induction Motor Drive Using MRAS with Neuro Fuzzy Adaptive Controller," International Journal of Electrical and Computer Engineering (IJECE), vol.8, no.5,pp. 2691-2702,Oct. 2018.

[9] Hamed, A. Hazzab,"Modeling and Real-Time Simulation of Induction Motor Using RT-LAB," International Journal of Power Electronics and Drive System (IJPEDS),vol. 9, no. 4, pp. 1476-1485, Dec. 2018.

[10] L. Jiri and K. Pavel,"Induction motor drive predictive direct torque control method," in 2015 25th International Conference Radioelektronika RADIOELEKTRONIKA, Pardubice, Czech Republic, pp. 70-74, Apr. 2015

[11] Beerten, J., J. Verveckken, and J. Driesen,"Predictive Direct Torque Control for Flux and Torque Ripple Reduction," IEEE Transactions on Industrial Electronics, vol. 57, no. 1 pp. 404-12, Jan. 2010.

[12] Nemec, M., D. Nedeljkovic, and V. Ambrozic,'Predictive Torque Control of Induction Machines Using Immediate Flux Control," IEEE Transactions on Industrial Electronics, vol. 54, no. 4, pp. 2009-2017, Aug. 2007

[13] J. Lettl and P. Karlovsky,'Induction motor drive predictive control method anaysis and comparison with fundamental direct torque control method," PIERS Proceedings, pp. 2510-2513, 2015.

[14] Scoltock, James, Tobias Geyer, and Udaya K. Madawala,"A Comparison of Model Predictive Control Schemes for MV Induction Motor Drives," IEEE Transactions on Industrial Informatics, vol. 9, no. 2, pp. 909-919, May 2013.

[15] Abad, G., M.A. Rodriguez, and J. Poza,"Two-Level VSC Based Predictive Direct Torque Control of the Doubly Fed Induction Machine With Reduced Torque and Flux Ripples at Low Constant Switching Frequency," IEEE Transactions on Power Electronics, vol. 23, no. 3, pp. 1050-1061, May 2008.

[16] S. Fan, J. Luo, and H. Zhang,"A Voltage Vector Prediction Direct Torque Control System for Induction Motor," in 2011 International Conference on Electrical and Control Engineering, Yichang, China, pp. 2873-2876, 2011.

[17] Vargas, R., Cortes, P., Ammann, U., Rodiguez, J., Pontt, J,"Predictive control of a three phase neutral point clamped inverter," IEEE Transactions on Industrial electronics, vol. 54(5), pp. 2697-2705, 2007.

[18] J. Rodriguez and P. Cortes, Predictive Control of Power Converters and Electrical Drives, first edition. John Wiley I\& Sons, Ltd, Chichester, UK, 2012.

[19] Himabindu, T., A. V. Ravi Teja, G. Bhuvaneswari, and B. Singh,"Simplified Predictive Torque Control of an IM Drive with Efficient Zero Vector Placement," in 2017 IEEE 26th International Symposium on Industrial Electronics (ISIE), Edinburgh, United Kingdom, pp. 362-367, 2017. 


\section{BIOGRAPHIES OF AUTHORS}
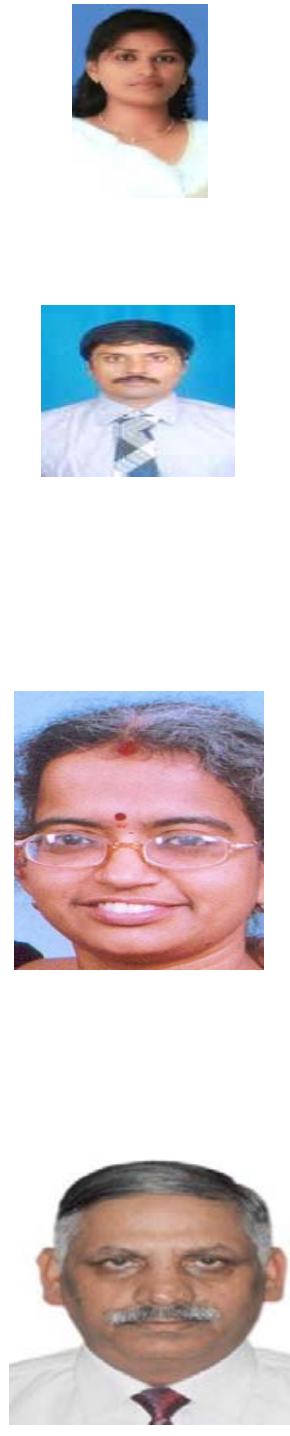

Himabindu.T received the B.Tech and M.Tech (Power Electronics and electric Drives) degree in electrical and electronics engineering from JNTU, Hyderabad, India, in 2007 and 2009 respectively. Her research areas of interest include electric machine drives, power electronics, multilevel inverters. Worked as an Assistant Professor in the Dept. of EEE, JPNCE, Mahabubnagar, India from July 2010 to Jan. 2013.Currently Ph.D Scholar in the department of electrical and Electronics Engineering, BITS-PILANI, Hyderabad, India since September, 2014.

A.V Ravi Teja received the B.E. degree in electrical and electronics engineering from Osmania University, Hyderabad, India, in 2008, and the M.Tech. degree in machine drives and power electronics specialization from the Indian Institute of Technology Kharagpur, Kharagpur, India, in 2010. PhD degree from the Department of Electrical Engineering, IIT Kharagpur in 2016. His research areas of interest include electric machine drives, power electronics, and control systems. He worked in RESCUES Project at Indian Institute of Technology Kharagpur from March 2016 to June 2016. Worked as an Assistant Professor, BITS Pilani Hyderabad Campus from July 2016 to May 2017. Currently he is working as an Assistant Professor in the Dept. of Electrical Engineering at Indian Institute of Technology Ropar, India since June 2017. Further info on his homepage: https://scholar.google.co.in/citations?user=wp5W3V8AAAAJ $\backslash \& a m p ; h l=e n$

G. Bhuvaneswari received the B.E. degree in electrical and electronics engineering from College of Engineering, Guindy, Anna University, Madras in 1985.She received M.Tech and Ph.D from IIT Madras in 1987 and 1992 respectively. Research interest with specific areas of involvement: Power Electronics, Electrical Machines, Drives, Power Supplies, Power conditioning, Power Quality, HVDC and Renewable energy. She worked as Senior Project Officer Gr II at Centre for ICl\&SR, IIT Madras from May 1988 to May 1992 and as a lecturer in the Dept. of EEE at college of engineering, Madras from June 1992 to Dec. 1993. She worked as a System Analyst at ComEd, Chicago, IL, USA from June 1994 to Jan. 1997. She joined as a faculty member in the Dept. of Electrical Engineering, IIT Delhi from Aug. 1997 to April 2011. She was a visiting professor in the Dept. of EEE, BITS-PILANI, Hyderabad campus, Hyderabad from July 2014 to May 2016. Presently she is working as a Professor in the Dept. of Electrical Engineering since April 2011 to till date at IIT Delhi, Delhi, India.

Further info on her homepage: http://ee.iitd.ac.in/people/gbhuv.html

Bhim Singh has received his B.E. (Electrical) from the University of Roorkee, India, in 1977 and his M.Tech. (Power Apparatus $1 \&$ Systems) and Ph.D. from the Indian Institute of Technology Delhi, India, in 1979 and 1983, respectively. His areas of interest include solar PV grid interface systems, microgrids, power quality monitoring and mitigation, solar PV water pumping systems, improved power quality AC-DC converters, power electronics, electrical machines, drives, flexible alternating transmission systems, and high voltage direct current systems. In 1983, he joined the Department of Electrical Engineering, University of Roorkee (Now IIT Roorkee), as a Lecturer. He became a Reader there in 1988. In December 1990, he joined the Department of Electrical Engineering, IIT Delhi, India, as an Assistant Professor, where he has become an Associate Professor in 1994 and a Professor in 1997. He has been ABB Chair Professor from September 2007 to September 2012. He has also been CEA Chair Professor from October 2012 to September 2017. He has been Head of the Department of Electrical Engineering at IIT Delhi from July 2014 to August 2016. Since, August 2016, he is the Dean, Academics at IIT Delhi. He is JC Bose Fellow of DST, Government of India since December 2015.Currently he is working as a professor in the Dept. of Electrical Engineering and Dean (Academics) at IIT Delhi, Delhi, India.

Further info on his homepage: http://web.iitd.ac.in/ bsingh/ 